\title{
cIAP1 and cIAP2 limit macrophage necroptosis by inhibiting Rip1 and Rip3 activation
}

\author{
S McComb ${ }^{1,2}$, HH Cheung ${ }^{2,3}$, RG Korneluk ${ }^{2,3}$, S Wang ${ }^{4}$, L Krishnan ${ }^{1,2}$ and S Sad ${ }^{\star, 1,2}$
}

Cellular inhibitor of apoptosis proteins (cIAPs) have emerged as important anti-cell death mediators, particularly in cancer. Although they are known to be expressed in immune tissue, their specific immune function remains unclear. We observed that degradation of cIAPs with SMAC mimetic (SM) results in death of primary bone-marrow-derived macrophages. SM-induced death of macrophages occurred by programmed necrosis (necroptosis), which was dependent on TNF receptor expression. Consistent with necroptosis, SM-induced death of macrophages was abrogated by inhibition of receptor interacting protein 1 (Rip1) kinase signaling or by receptor interacting protein 3 (Rip3) knockdown. SM-induced necroptosis was also dependent on inhibition of SM-induced apoptosis due to the expression of the endogenous caspase inhibitor, XIAP. We found that cIAPs limit Rip3, and to a lesser extent Rip1, expression via post-transcriptional mechanisms, leading to inhibition of the Rip1-Rip3 death complex (necrosome). Reduced cIAP activity in vivo, via SM treatment or specific knockout of either cIAP, resulted in elevated macrophage cell death and compromised control of an intracellular bacterium, Listeria monocytogenes. These results show that cIAPs have an important role in limiting programmed necrosis of macrophages, which facilitates effective control of a pathogen.

Cell Death and Differentiation (2012) 19, 1791-1801; doi:10.1038/cdd.2012.59; published online 11 May 2012

Innate immune cells are vital to controlling pathogens. Macrophages mediate phagocytosis of pathogens and initiate immune responses through the release of inflammatory cytokines. ${ }^{1}$ In order to function effectively, macrophages must be capable of resisting the cytotoxic microenvironments of infected tissue. Activated macrophages also carry high levels of potentially toxic reactive oxygen species (ROS) and inflammatory cytokines. ${ }^{2}$ Thus, during differentiation, macrophages are known to upregulate expression of multiple anti-cell death mediators. ${ }^{3-5}$

Classically, cell death is thought to be initiated by regulated signaling, known as apoptosis, or by an unregulated mechanism from cellular damage, known as necrosis. This simple paradigm has been challenged by findings that necrosis can be the result of programmed signaling., Programmed necrosis (necroptosis) can be specifically blocked by necrostatin-1 (Nec-1), a small-molecule inhibitor of the kinase activity of receptor interacting protein 1 (Rip1). ${ }^{8}$ Necroptosis is generally regarded as an alternative death pathway, activated when caspase-mediated death is inhibited. ${ }^{9}$ Under survival conditions Rip1 is ubiquitinated by the cellular inhibitors of apoptosis proteins (CIAP1 and clAP2). ${ }^{10}$ A complex involving ubiquitinated Rip1, clAPs, and the TNF- $\alpha$ receptor can drive the activation of $\mathrm{NF}-\kappa \mathrm{B}$ signaling. ${ }^{7,9}$ Recently it was shown that clAP1 inhibition in tumor cells increases the sensitivity to TNF-induced necroptosis. ${ }^{11,12}$ Under these conditions, Rip1 becomes deubiquitinated and forms a kinase-active, necroptosis-inducing complex with receptor interacting protein 3 (Rip3) and Fas-associated death domain (FADD) called the necrosome. ${ }^{11,13}$ Alternatively, deubiquitinated Rip1 can also promote caspase-8-mediated apoptosis under some conditions. ${ }^{14}$ The exact targets of the necrosome have yet to be elucidated, although its activity generally precedes increased ROS production, loss of plasma membrane integrity, and necrotic cell death. ${ }^{15}$

Although increased macrophage cell death is a documented mechanism for immune evasion by intracellular bacteria, ${ }^{16,17}$ the possible role of necroptosis during infection is not clear. In addition, the mechanisms that control immune cell susceptibility to necroptosis are unknown. In tumor cells, high expression levels of clAPs are associated with resistance to cell death. ${ }^{18,19}$ Similarly, increased clAP expression during immune activation $^{20}$ may represent a novel mechanism to protect macrophages. In this report, we evaluate the role of clAP1 and clAP2 in macrophages. Using SM-164 (SM), a mimetic of the SMAC protein that induces rapid and specific degradation of the clAPs, ${ }^{21}$ we show that clAP expression protects macrophages from Rip1-dependent necroptotic cell death and facilitates pathogen control.

\footnotetext{
${ }^{1}$ NRC-Institute for Biological Sciences, Ottawa, Ontario, Canada; ${ }^{2}$ Deptartment of Biochemistry, Microbiology and Immunology, University of Ottawa, Ottawa, Ontario, Canada; ${ }^{3}$ Apoptosis Research Centre, Children's Hospital of Eastern Ontario, Ottawa, Ontario, Canada and ${ }^{4}$ Department of Internal Medicine, Pharmacology and Medicinal Chemistry, University of Michigan, Ann Arbor, MI, USA

*Corresponding author: S Sad, NRC-Institute for Biological Sciences, 1200 Montreal Road, Building M-54, Ottawa, Ontario K1A 0R6, Canada. Tel: +1613 993 6015; Fax: +1613 941 4475; E-mail: subash.sad@ nrc.ca

Keywords: innate immunity; macrophage; inflammation; host-pathogen interactions

Abbreviations: CIAP, cellular inhibitors of apoptotic proteins; xIAP, x-linked inhibitor of apoptosis protein; FLIP, FLICE-like inhibitory protein; SMAC, second mitochondria-derived activator of caspases; RIP, receptor interacting protein; TNF, tumor necrosis factor; Nec-1, necrostatin-1; ROS, reactive oxygen species; FADD, Fas-associated death domain; LM, Listeria monocytogenes; BMDMs, bone-marrow-derived macrophages

Received 17.10.11; revised 06.3.12; accepted 27.3.12; Edited by A Villunger; published online 11.5.12
} 


\section{Results}

SMAC mimetic induces degradation of both cIAP1 and clAP2, resulting in the death of macrophages. We first addressed the function of clAPs in macrophages by treating bone-marrow-derived macrophages (BMDMs) with varying concentrations of the SM for $4 \mathrm{~h}$. SM treatment rapidly degraded clAPs, consistent with previous work in tumor cells $^{21}$ (Figure 1a). SM caused degradation of clAPs at low concentrations (50 $\mathrm{nM})$ but required higher doses $(\sim 1-5 \mu \mathrm{M})$ for complete degradation. Measuring loss of plasma membrane integrity through propidium iodide (PI) uptake, SM-treated macrophages began dying by $4 \mathrm{~h}$ with almost complete cell death by $24 \mathrm{~h}$ (Figures $1 \mathrm{~b}$ and $\mathrm{c}$ ). We also utilized the MTT assay to confirm dose-dependent loss of cell viability with SM for $24 \mathrm{~h}$ (Figure 1d). Furthermore, we confirmed that the loss of viability is correlated with cell death as detected by $\mathrm{LDH}$ release in the culture supernatant (Figure 1d). The murine macrophage cell line J774A1 showed similar increased cell death after SM treatment (Supplemental Figure 1A).

We next confirmed that SM treatment induced the degradation of both forms of clAP. Using either clAP1- or clAP2-deficient macrophages we noted that SM treatment resulted in the degradation of either cIAP protein (Figure 1e). Using similar doses of SM $\mathrm{ClAP}^{-/-}$and $\mathrm{ClAP} 2^{-/-}$macrophages showed an elevated loss of viability relative to WT cells (Figure 1f). Thus, it appears that clAP1 and clAP2 are additively redundant in limiting cell death in macrophages.

SM-induced cell death occurs through caspaseindependent programmed necrosis (necroptosis). clAPs

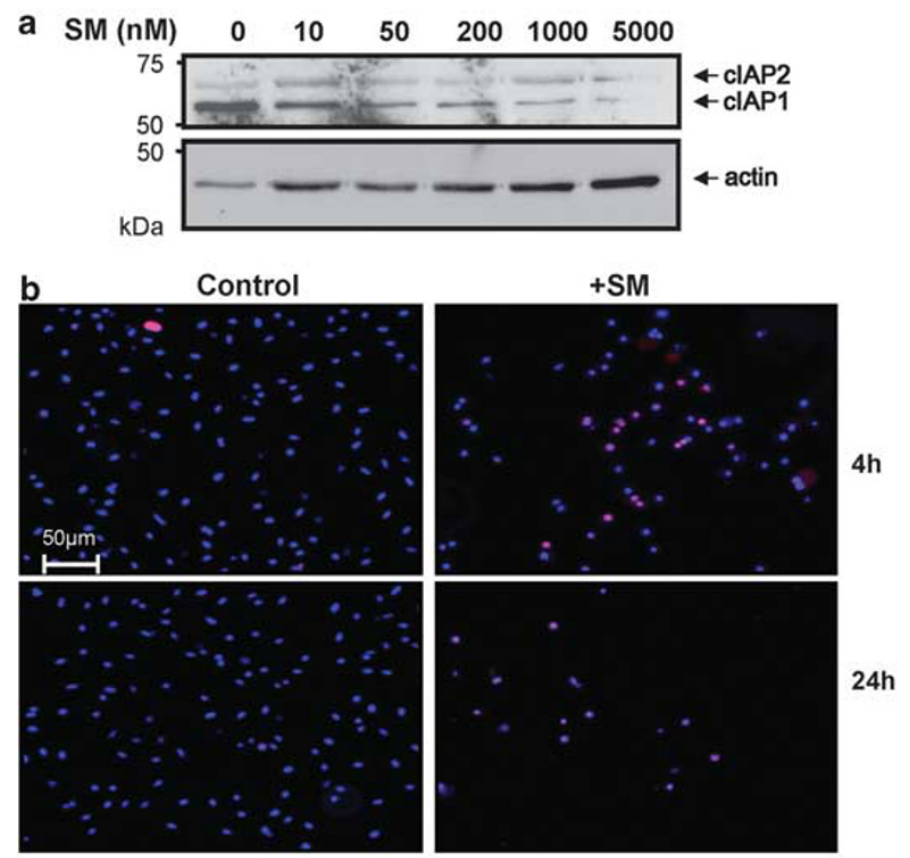

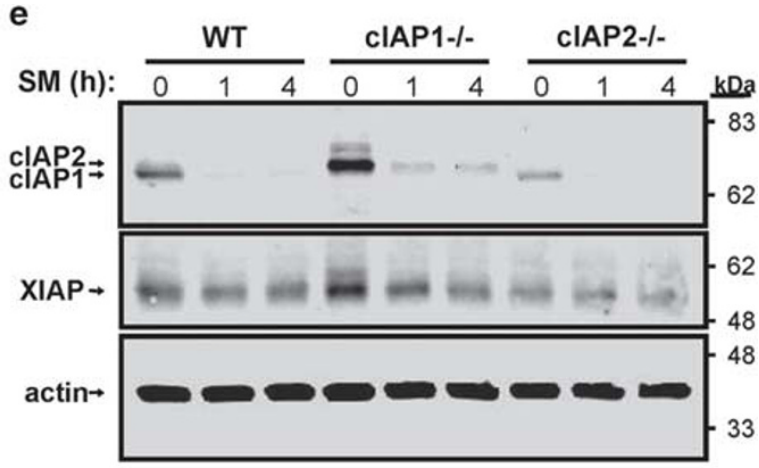

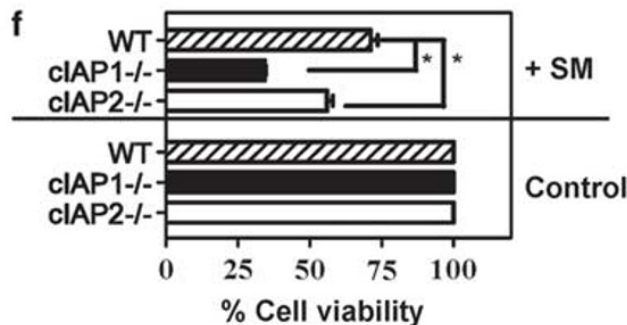

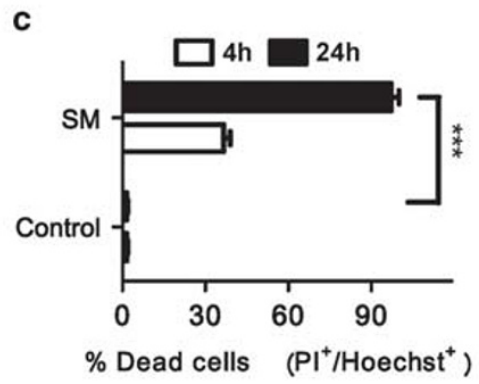

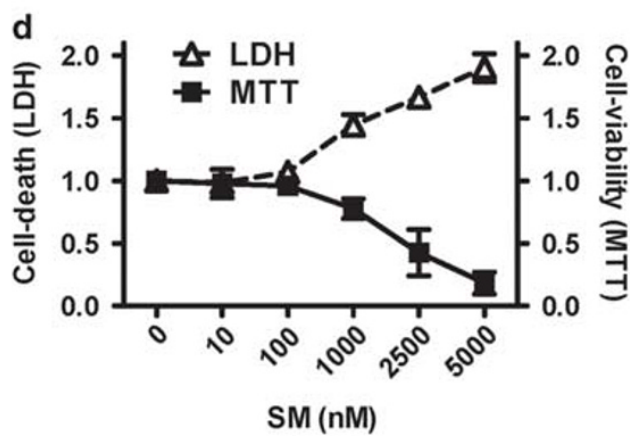

Figure 1 SMAC mimetic treatment results in degradation of both CIAP1 and CIAP2, and drives cell death of macrophages. Bone-marrow-derived macrophages were incubated in the presence of SM at various concentrations. (a) After $4 \mathrm{~h}$ of treatment with varying concentrations of SM as shown, macrophages were lysed and examined for clAP expression via western blot. (b and $\mathbf{c}$ ) Bone marrow cells were treated directly in culture flasks with or without SM $(5 \mu \mathrm{M})$, viability was examined by quantifying the proportion of cells positive for propidium iodide (red) over the total number of cells (Hoechst ${ }^{+}$: blue). The average percentage of dead cells from five random fields was used. (d) After $48 \mathrm{~h}$, cell viability over a range of concentrations was also assessed using MTT assay. Cell supernatants were also examined for LDH release (dashed line). Results shown are representative for three repeated experiments performed in duplicate. ${ }^{* \star} P<0.001$. (e) Bone-marrow-derived macrophages were generated from WT, clAP1 ${ }^{-1}$ and clAP2 ${ }^{-1-}$ mice. Macrophages were then placed in six-well plates $\left(10^{6} \mathrm{cells} /\right.$ well) and exposed to SM (5 $\left.\mu \mathrm{M}\right)$ for 0,1 or $4 \mathrm{~h}$. Cells were then analyzed by western blot for expression of IAPs. (f) Knockout and WT macrophages were plated in 96-well plates with and without SM. After $24 \mathrm{~h}$, cells were analyzed for viability via MTT assay. Graphs show the average viability of cells relative to the appropriate untreated control. ${ }^{*} P<0.05$ 

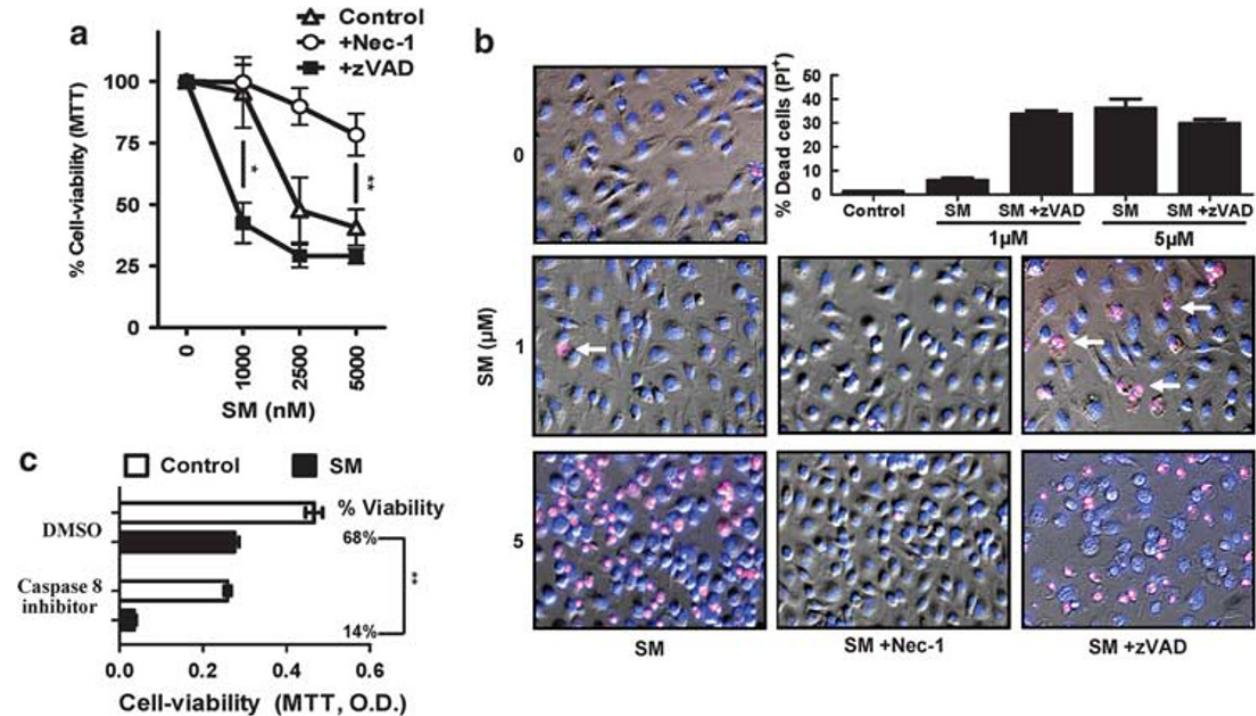

SM

$\mathrm{SM}+\mathrm{Nec}-1$

$\mathrm{SM}+\mathrm{zVAD}$

Figure 2 SM-induced death occurs by necroptosis. Macrophages were placed in 96 -well plates ( $3 \times 10^{4} \mathrm{cells} /$ well) and cultured with or without SM and various inhibitors as shown (Inhibitors at $50 \mu \mathrm{M}$ ). (a) At $24 \mathrm{~h}$ in culture with varying amounts of SM, necrostatin and/or zVAD, cells were analyzed for viability by MTT assay. Results show the mean \% viability (relative to untreated cells) from two repeated experiments performed in duplicate. ${ }^{*} P<0.05$; ${ }^{* *} P<0.005$. (b) Viability results were confirmed using Hoechst (blue) and Propidium iodide (red) co-staining to identify cell death (magenta) at $4 \mathrm{~h}$ post treatment. The bar graph shows the average proportion of $\mathrm{PI}^{+}$cells at various SM concentrations with necrostatin and/or ZVAD co-treatment, taken from five random fields per treatment. Similar results were observed in three repeated experiments performed in triplicate. (c) After $48 \mathrm{~h}$ in culture with a specific caspase-8 inhibitor (z-IETD-CHO) and/or SM treatment, cells were analyzed for viability by MTT assay. Results presented were performed in duplicate

were initially identified as direct inhibitors of caspases, ${ }^{22}$ although recent evidence has indicated that this may not be their main role. ${ }^{23}$ Thus, in order to assess whether the death from SM treatment occurred due to deinhibition of apoptotic caspases, BMDMs were treated with SM and a pan-caspase inhibitor (z-VAD-FMK). Surprisingly, inhibition of caspases was not only unable to prevent SM-induced death of macrophages, but there was a significant increase in sensitivity to SM. This clearly suggests that caspases are having a protective role in macrophages (Figures 2a and b). Using a specific inhibitor of caspase-8, we also observed an increase in SM-induced cell death (Figure 2c). Additionally, we observed minimal increases in cleavage of fluorogenic caspase substrates after SM treatment (data not shown). These results indicate that SM-induced death occurs by a non-apoptotic pathway.

Necroptosis is an alternative form of cell death usually revealed when caspase activity is inhibited. ${ }^{7,24}$ We thus hypothesized that SM-induced death may be occurring through necroptosis. To test this, we co-treated macrophages with SM and the specific inhibitor of Rip1 kinase, Nec-1. ${ }^{24}$ Whereas caspase inhibition increased sensitivity of macrophages to SM, Nec-1 completely abrogated SM-induced loss of viability (Figures $2 a$ and $b$ ). Cell death results were confirmed by co-staining for cell nuclei (Hoechst) and plasma membrane integrity via $\mathrm{Pl}$ exclusion (Figure $2 b$ ). We also utilized live fluorescence microscopy to confirm that SM induced a loss of mitochondrial activity followed by rapid cell death (Supplemental Video 1). In contrast, cells treated with Nec-1 and SM showed no loss of mitochondrial function over a similar time period (Supplemental Video 2).

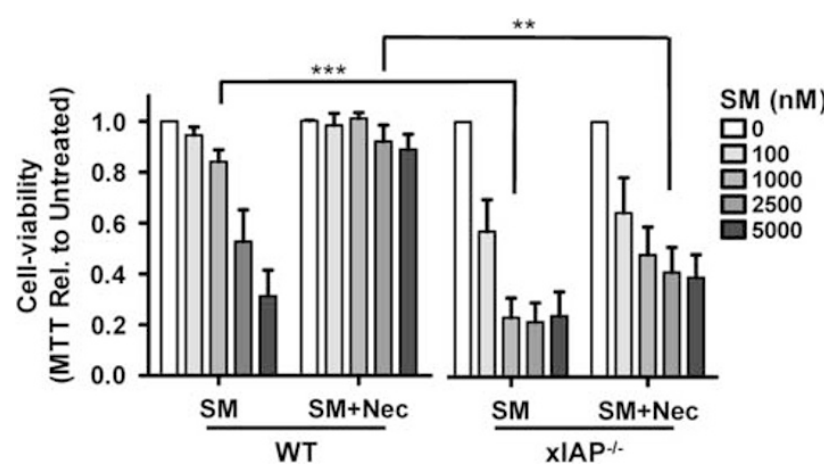

Figure 3. XIAP expression protects macrophages from SM-induced apoptosis. Bone marrow macrophages were derived from WT and XIAP ${ }^{-1-}$ donor mice. Cells were then treated with varying concentrations of SM, with or without the addition of necrostatin, for $24 \mathrm{~h}$ and examined for viability via MTT assay. Experiments were performed four times in triplicate. ${ }^{\star \star *} P<0.001 ;{ }^{* \star} P<0.005$

X-linked inhibitor of apoptosis (XIAP) inhibits SMinduced apoptosis. The specific SM we have utilized (SM164) may also antagonize the $x$-linked inhibitor of apoptosis protein (xIAP) without specific degradation. ${ }^{21}$ Unlike cIAPs, XIAP is a strong inhibitor of caspase activity. ${ }^{25}$ Utilizing $\mathrm{XIAP}^{-1-}$ BMDMs we observed significantly increased sensitivity to SM relative to WT cells (Figure 3). Interestingly, we were unable to reverse the effects of SM in $\mathrm{XIAP}^{-1-}$ macrophages through co-treatment with $\mathrm{Nec}-1$ (Figure 3). Only using a combination of ZVAD and Nec were the effects of SM in XIAP ${ }^{-1-}$ macrophages somewhat abrogated (data not shown). Thus, our data indicate that 
xIAP expression appears to prevent the induction of apoptosis by SM. Furthermore, XIAP expression is necessary for SM-induction of the alternate pathway of necroptosis.

SM treatment results in increased Rip3 expression and Rip1/Rip3 complex (necrosome) formation. Rip1 and Rip3 are critical mediators of necroptosis, ${ }^{11,26}$ thus we investigated changes in their expression induced by SM treatment. We first examined Rip1 following SM treatment, where alongside cIAP degradation we observed an increase in a slower migrating form of Rip1 (Figure 4a). The slower migrating band of Rip1 has been previously shown to be the phosphorylated form of Rip1. ${ }^{27}$ We confirmed this by treating cell lysates with lambda phosphatase, which resulted in loss of the slower migrating band (Supplemental Figure 2A). Nec-1 treatment also resulted in less Rip1 phosphorylation (Figure 4a). We noted similar changes in Rip1 phosphorylation in J774A1 cells (Supplemental Figure 1B). In addition to increased Rip1 phosphorylation, we observed an upregulation of Rip3 kinase expression within minutes of SM treatment. Consistent with necroptosis, immunoprecipitation experiments revealed that Rip1 shows less association with ClAP and more with Rip3 following SM treatment
(Supplemental Figure 2B). The endogenously expressed modulator of caspase-8 activity, FLIP, has also been shown to effect the induction of necroptosis. ${ }^{28}$ We observed a small increase in the short form of FLIP (FLIP(S)) following SM treatment (Figure 4a). Within J774A1 cells, the induction of FLIP(S) following SM treatment was much more apparent (Supplemental Figure 1B). These data indicate that FLIP(S) expression may have a role in SM-induced necroptosis.

Using the densitometry measurements from three separate western blot experiments we observed a consistent increase in Rip3 expression by $1 \mathrm{~h}$ post-SM treatment, with a smaller increase in Rip1 expression (Figure 4b). It is important to note that we observed relatively low levels of overall Rip3 expression that were only detectable using the highly sensitive Supersignal West Femto chemiluminescence substrate. Using qRT-PCR we observed a minor increase in Rip1 and Rip3 mRNAs ( 1.25 fold), with a consistent downregulation by $4 \mathrm{~h}$ after SM treatment (Figure $4 \mathrm{c}$ ). On the basis of this and the speed of their upregulation, we hypothesize that increased expression of Rip3, and to a lesser extent Rip1, occurs due to decreased turnover of Rips following SM treatment. Consistent with this, treatment with pan-caspase inhibitor zVAD, or the 20s proteasome inhibitor

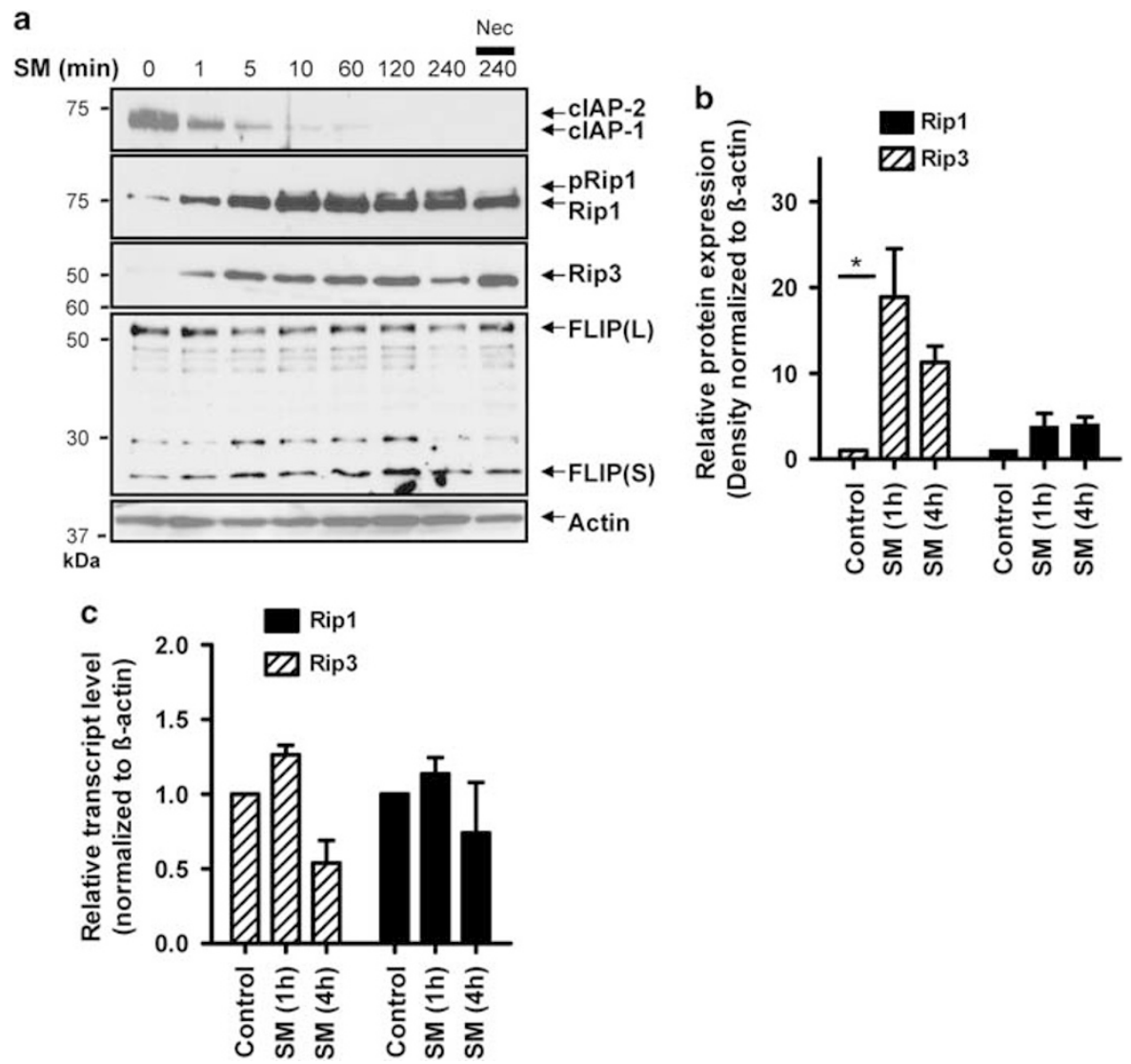

Figure 4 SM induces Rip1/Rip3 necrosome activation. (a) Bone-marrow-derived macrophages were placed in a 24-well plate at $3 \times 10^{5}$ cells per well. Cells were then stimulated for various time intervals with SM and/or Nec-1 as indicated. Cell lysates were analyzed for expression of clAP, Rip1, Rip3 and FLIP via western blot. (b) Three separate western blot experiments were performed (as described in a) and examined by densitometry using ImageJ software. The mean expression level of Rip1 and Rip3 normalized to actin and relative to untreated control is shown. ${ }^{*} P<0.05$. (c) Bone-marrow-derived macrophages were stimulated with SM for 1 or $4 \mathrm{~h}$ as indicated. Cell lysates were then used to isolate RNA for qRT-PCR analysis. The average relative transcript level of Rip1 and Rip3 relative to untreated control and normalized to actin is shown from three separate experiments performed in duplicate 
lactacystin, resulted in increased expression of both Rips (Supplemental Figure 3). Thus our data indicate that clAPs may enhance proteolytic degradation of Rip1 and Rip3 kinases.

To confirm the importance of Rip3 in SM-induced cell death, we utilized targeted siRNA knockdown of Rip3. For optimal transfection efficiency we utilized a mouse macrophage cell line (J774A1). The siRNA knockdown of Rip3 was confirmed at $48 \mathrm{~h}$ by western blot (Figure $5 \mathrm{a}$ ), whereas Rip1 expression was not affected (data not shown). While Rip3 siRNA treatment did not influence cell viability without treatment,

a

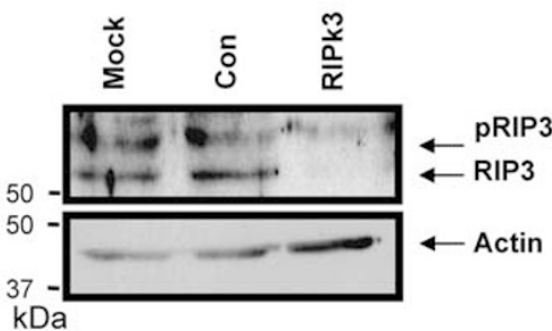

b

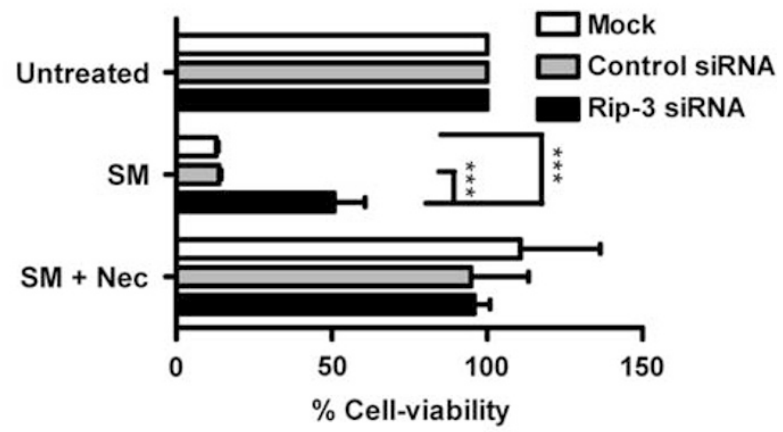

C

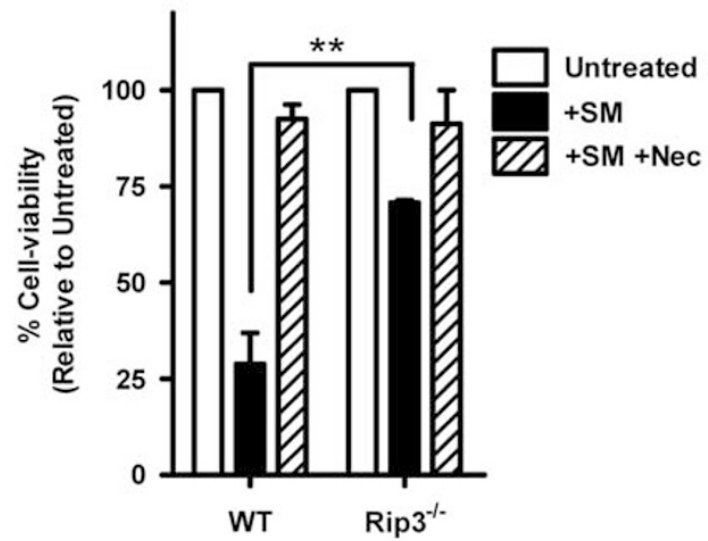

Figure 5 SM-induced macrophage cell death is Rip3 dependent. J774A1 mouse macrophages cells were placed at $2 \times 10^{4}$ cells per well in 96-well plates, and exposed to siRNA treatment ( $100 \mathrm{nM}$ ) as shown for $48 \mathrm{~h}$. (a) siRNA knockdown of Rip3 was confirmed after $48 \mathrm{~h}$ by western blot. Cells were first treated with SM for $3 \mathrm{~h}$ to stimulate Rip3 expression. (b) SM or SM + Nec was added to cells, with the addition of $50 \mu \mathrm{l}$ of media. Cells were then analyzed for viability after $24 \mathrm{~h}$, using MTT assay for mitochondrial activity. Results are representative of three repeated experiments, each performed in triplicate, ${ }^{* *} P<0.001$. (c) Bone marrow macrophages were derived from WT and Rip3 ${ }^{-1-}$ donor mice and treated for $24 \mathrm{~h}$ with $\mathrm{SM}+\mathrm{I}-\mathrm{Nec}$ as indicated. Cells were examined for viability after $24 \mathrm{~h}$ using MTT assay. Results show the means of three experiments performed in triplicate. ${ }^{* \star} P<0.005$
Rip3 knockdown resulted in a significant ( $\sim 50 \%)$ rescue of cells exposed to SM (Figure $5 \mathrm{~b}$ ). We also evaluated the effect of SM in Rip3-deficient macrophages. As expected, Rip3-deficient BMDMs were highly resistant to SM-induced cell death (Figure $5 \mathrm{c}$ ). We observed a similar increase in pRip1 and FLIP(S) in Rip3 ${ }^{-1-}$ macrophages as in WT cells, indicating that these mechanisms remain intact in the absence of Rip3 expression (Supplemental Figure 4). This datum confirms that SM-induced macrophage cell death occurs via Rip1-Rip3-mediated necroptosis.

SM-induced necroptosis is TNF-R dependent. Previous investigations into necroptosis have identified the TNF receptor as the central inducer of necroptosis. ${ }^{10,13,26}$ Thus, we examined TNF signaling in SM-induced macrophage death by utilizing BMDMs from mice deficient in TNF receptors 1 and $2\left(\mathrm{TNF}-\mathrm{R} 1 / 2^{-I-}\right)$. We observed that in the absence of TNF-R, there was minimal cell death following $\mathrm{SM}$ treatment (Figure 6a). Examination of TNF-R1/2-1macrophages by western blot showed no change in Rip1 or Rip3 in response to SM treatment (Figure 6b). Interestingly, macrophages lacking TNF-R appear to have higher basal expression of both Rip1 and Rip3, suggesting that the TNF-R may have a significant role in the degradation of Rips. We also utilized fluorescence microscopy to examine localization of Rip kinases following SM treatment. We observed that Rip1 and Rip3 show increased co-localization with the TNF-R at the cell membrane following SM treatment (Figure 6c). Finally, we confirmed increased association of Rip1 with the TNF-R using co-immunoprecipitation (Figure 6d). Thus, our data indicate that SM-induced degradation of clAPs results in the association of Rip kinases at the TNF-R.

In vivo administration of $S M$ results in increased macrophage necrosis. We assessed the in vivo effects of clAP degradation by injecting mice with $\mathrm{SM}(5 \mathrm{mg} / \mathrm{kg})$ intraperitoneally. At $6 \mathrm{~h}$ post treatment, we noted a drop in the expression of clAP1 and clAP2 in spleen and peritoneum (Figure 7a). Decreased clAP expression corresponded with increased macrophage $\left(\mathrm{F} 4 / 80^{+} \mathrm{CD} 11 \mathrm{~b}^{+}\right)$cell death, as determined by loss of $\mathrm{PI}$ exclusion (Figure $7 \mathrm{~b}$ ). To examine the effects of repeated dosing, we injected mice with SM daily (i.p.) for 4 days and examined peritoneal cells by flow cytometry. Macrophage numbers were significantly reduced in SM-treated mice, whereas $T$ cells had no significant change (Figure 7c). We also saw no change in the peritoneal pools of dendritic cells, B cells, and NK cells (Supplemental Figure 5). These data show that SM treatment causes increased macrophage death in vivo, and repeated injection can lead to significantly diminished macrophage numbers.

In vivo SM treatment increases susceptibility to bacterial infection. Next, we evaluated whether SM-induced death of macrophages in vivo influences susceptibility to a pathogen. We infected mice with the intracellular bacterium, Listeria monocytogenes (LM), as it causes illness in immune compromised hosts, with the innate immune system having a key role in control of infection. ${ }^{29}$ At 3 days post infection we found that SM-treated mice showed an approximately 10 -fold 


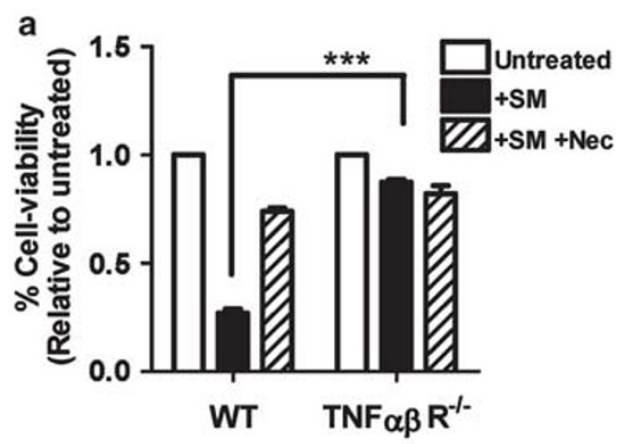

b
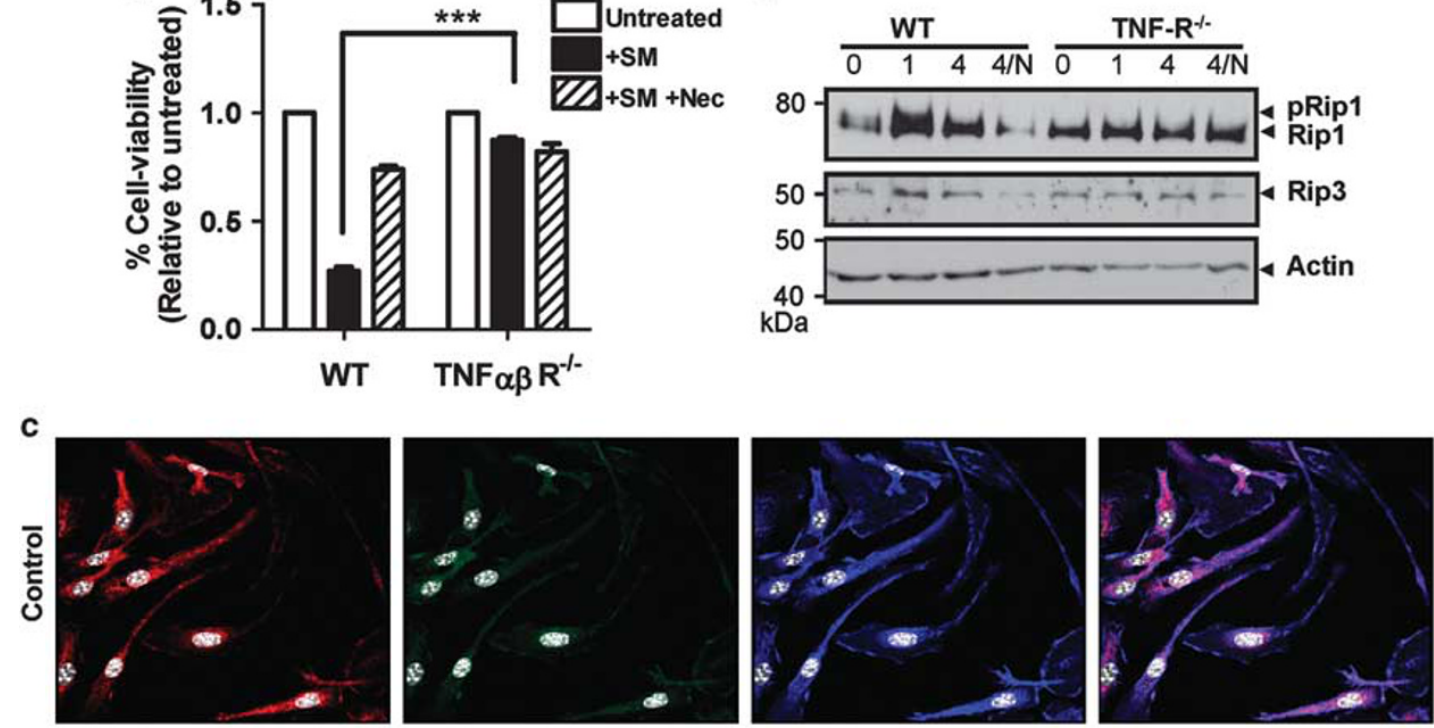

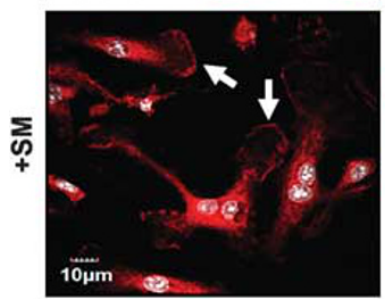

Rip1

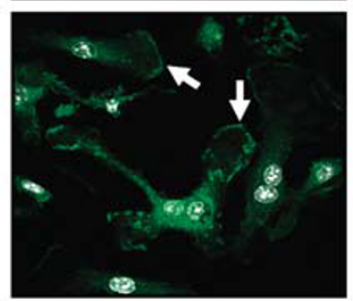

Rip3

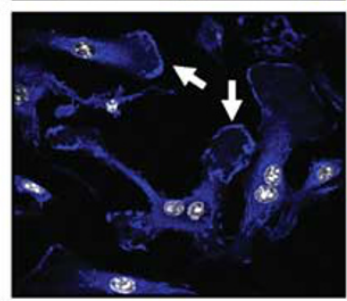

TNFR1

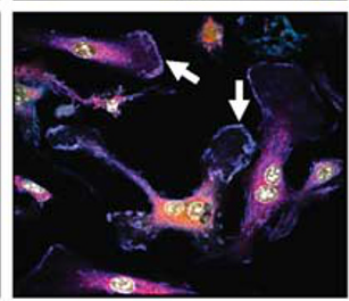

Merge

d

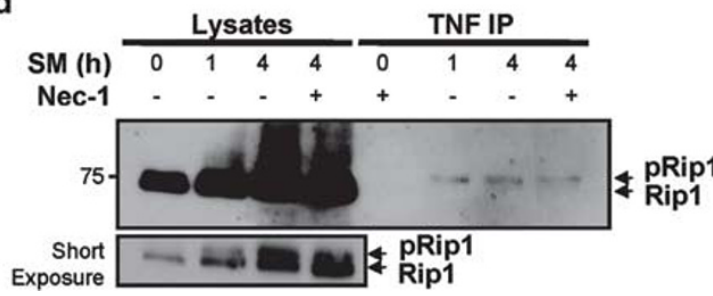

Figure 6 SM-induced necroptosis is TNF-R dependent. Bone marrow macrophages were derived from WT and TNFR $1 / 2^{-1-}$ mice and treated for $24 \mathrm{~h}$ with SM $(5 \mu \mathrm{M})$ or SM/necrostatin. (a) The viability of cells after SM treatment was measured using MTT assay. Similar results were observed in three repeated experiments performed in triplicate. (b) Bone marrow macrophages from WT and TNFR1/2 $2^{-1-}$ mice were exposed to SM $+1-$ Nec for varying time intervals as indicated. Cell lysates were then examined for Rip1 and Rip3 expression via western blot. (c) Bone-marrow-derived from WT macrophages were grown on cover slips in six-well plates and exposed to SM for $4 \mathrm{~h}$. After staining with antibodies for TNF-R (blue), Rip1 (red) and Rip3 (green), cells were examined via fluorescent confocal microscopy. Images show an extended focus image composed of 10 overlaid z-stack images. (d) WT and TNFR1/2 ${ }^{-1}$ macrophages were treated with SM $+/-$ Nec for varying time as shown and lysed using RIPA buffer. Co-immunoprecipitation was then performed using Protein-G sepharose beads and an antibody targeting TNF-R1

increase in LM burden in both the peritoneum and spleen (Figure 8a). This correlated to decreased numbers and increased cell death of macrophages in SM-treated mice, while T-cell pools were largely unaffected (Figures $8 \mathrm{~b}$ and $\mathrm{c}$ ). Thus, SM-induced macrophage death can lead to significantly compromised control of a bacterial pathogen.

cIAP1 or clAP2 deficiency increases macrophage necrosis and decreases control of bacteria. Finally, we determined the separate role of clAPs in limiting macrophage death in vivo. Thus, we compared the ability of ClAP1- or clAP2-deficient mice to control LM infection. At 3 days post infection, we observed that both $\mathrm{ClAP}^{-1-}$ and $\mathrm{clAP} 2^{-1-}$ mice had higher bacterial burden when compared with WT mice (Figure 9a). Consistent with additive redundance in limiting necroptosis, both CIAP1- and ClAP2-deficient mice showed lower peritoneal macrophage numbers (Figures 9b and c) and elevated macrophage cell death compared with WT mice (Figures $9 \mathrm{~b}$ and $\mathrm{c}$ ). To further confirm that clAP1 and clAP2 are important in control of macrophage necrosis, we utilized SM to degrade compensatory clAP2 expression in clAP1-deficient mice during LM infection. Indeed, SM treatment increased bacterial burden at day 3 post infection relative to untreated $\mathrm{ClAP}^{-1-}$ mice (Supplemental Figure 6). Thus, these findings support the conclusion that 


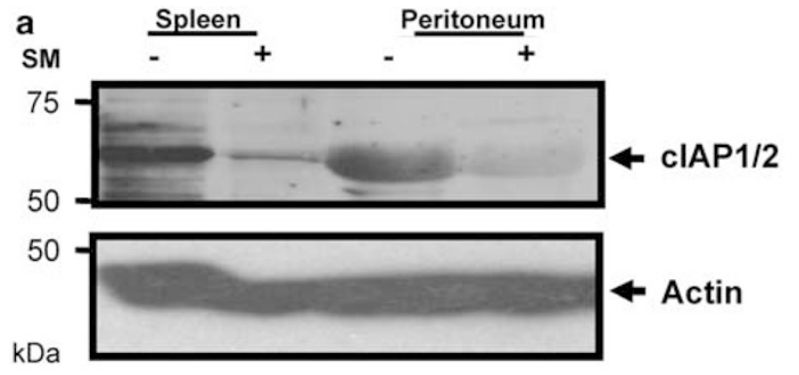

a
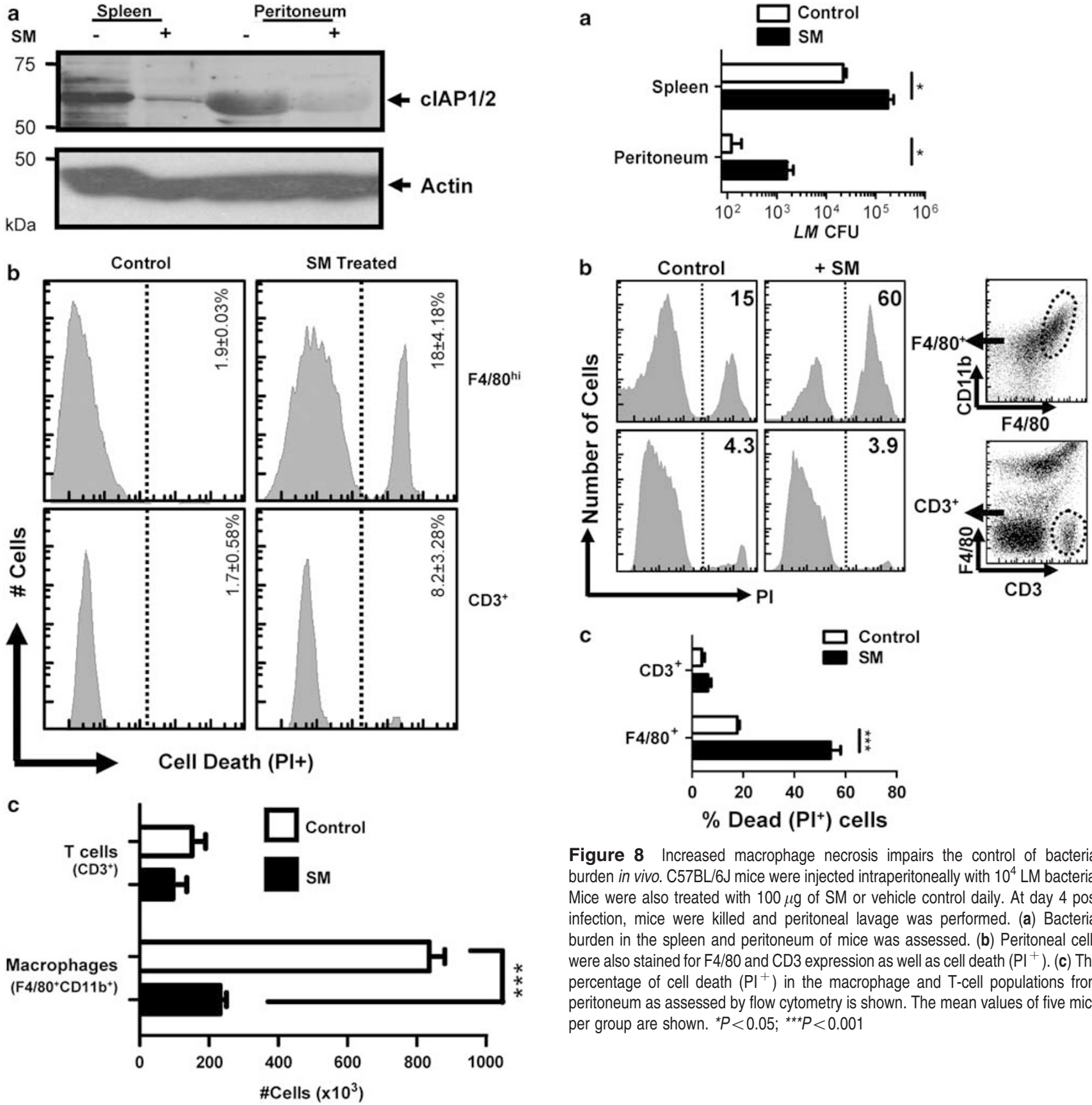

Figure 7 In vivo administration of SM results in rapid CIAP degradation and macrophage cell death. C57BL/6J mice were injected intraperitoneally with $100 \mu \mathrm{g}$ of SM164. After $6 \mathrm{~h}$, control and treated mice were killed and peritoneal lavage was performed. (a) An equal number of spleen and peritoneal cells were lysed and analyzed by western blot for expression of cIAP. (b) Peritoneal cells were stained for macrophage cell markers and cell death $\left(\mathrm{PI}^{+}\right)$. Histograms show gated populations of $\mathrm{F} 4 / 80^{+} \mathrm{CD}_{11 \mathrm{~b}^{+}}$macrophages or $\mathrm{CD}^{+}{ }^{+} \mathrm{T}$ cells as labeled. Results are representative of at least three mice analyzed per treatment group. The mean percentages of dead cells for three mice per group ( \pm S.E.M.) are shown. (c) Mice were injected daily (IP) with $100 \mu \mathrm{g}(\sim 5 \mathrm{mg} / \mathrm{kg})$ of SM164. At day 4, mice were killed and peritoneal lavage was performed. Cells were stained and analyzed by flow cytometry. Graphs show the average number of $\mathrm{F} 4 / 80^{+}$and $\mathrm{CD}^{+}$cells within these populations. Similar results were obtained in two experiments each with $n \geq 3$ mice per group. ${ }^{* *} P<0.001$

CIAP1 and clAP2 have an additive anti-necroptotic function within macrophages.

\section{Discussion}

The innate immune system provides the first-line of defense against a myriad of pathogens. Macrophages are critical innate immune cells that mediate protection through phagocytosis of pathogens and expression inflammatory immune molecules. Indeed, protection against primary LM infection in immunocompetent hosts is mediated mainly by the innate immune system. ${ }^{29}$ It is known that innate immune cells upregulate expression of clAPs during differentiation and activation, ${ }^{4,20,30}$ however, their function during an immune 
a

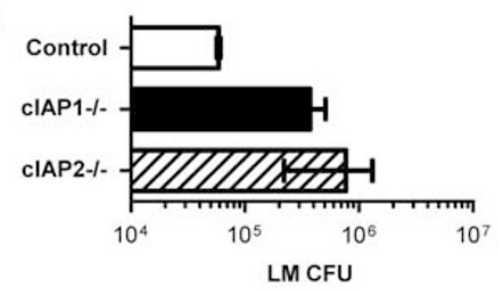

b
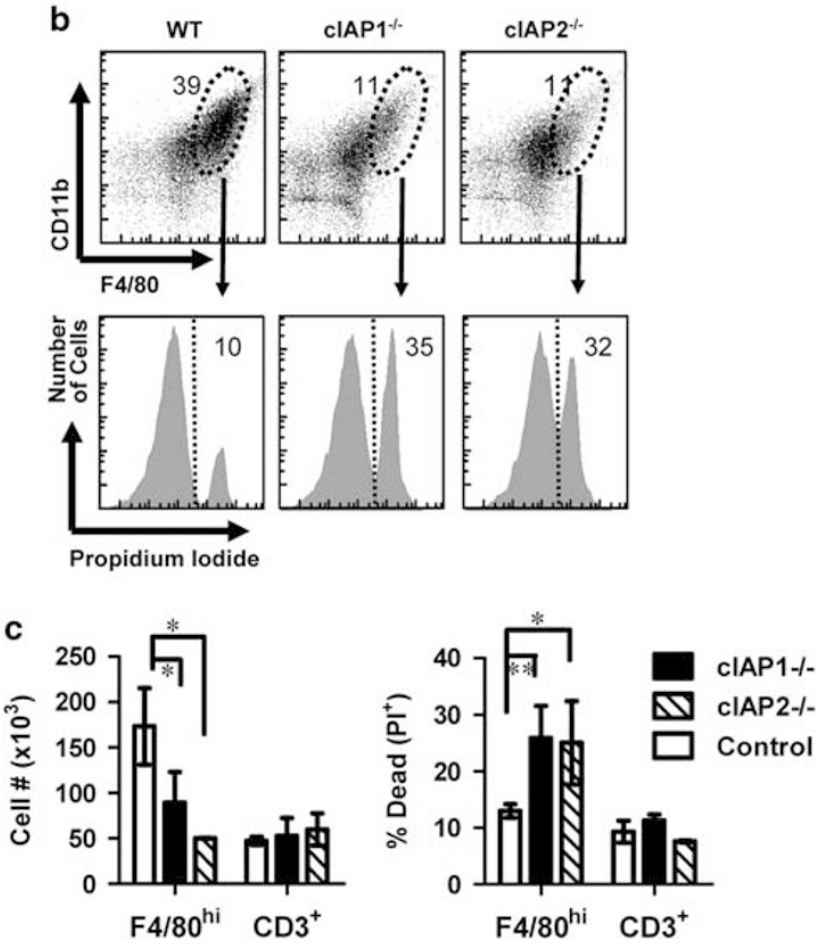

Figure 9. $\mathrm{ClAP}^{-/-}$and $\mathrm{ClAP} 2^{-/-}$mice exhibit elevated macrophage necrosis and decreased control of LM burden relative to WT mice. Mice were injected with LM (IP). At day 3 post-infection, mice were killed and peritoneal lavage was performed. (a) Peritoneal bacterial burden of knockout and WT mice was assessed. (b) Peritoneal cells were also stained for F4/80, CD11b and CD3 expression. Gated populations of $\mathrm{CD} 11 \mathrm{~b}^{+} \mathrm{F} 4 / 80^{\text {high }}$ cells were examined for cell death $\left(\mathrm{PI}^{+}\right)$by flow cytometry. (c) The numbers of $\mathrm{T}$ cells $\left(\mathrm{CD} 3^{+}\right)$and macrophages $\left(\mathrm{F} 4 / 80^{+} \mathrm{CD} 11 \mathrm{~b}^{+}\right)$, as well as the percentage of dead cells $\left(\mathrm{PI}^{+}\right)$for each population, were evaluated and examined as shown. ${ }^{* *} P<0.001$; ${ }^{*} P<0.05$, $n \geq 3$ mice per group

response remains unclear. In this report we thus examined the in vitro and in vivo role of clAPs in macrophages.

Our results show that the degradation of clAPs through application of SMAC mimetic (SM) results in macrophage cell death. This result appears to contradict a recent report showing that human monocytes are susceptible to SMinduced cell death whereas macrophages are resistant. ${ }^{31}$ The difference in macrophage viability results may be due to the reduced concentrations of a different SM, BV6, which was employed in that study. ${ }^{31}$ In our study, we employed higher concentrations of SM to induce complete degradation of clAPs. ${ }^{21}$ The necessity for more SM may be driven by higher clAP expression within macrophages. Furthermore, minor differences between murine and human clAPs may also necessitate higher doses of SM. Importantly, the in vitro dose of SM utilized here is biologically relevant, as it is consistent with tissue concentrations in previously reported in vivo experiments. $^{21}$

The abrogation of SM-induced cell death by necrostatin or Rip3 knockdown clearly pinpoints the mechanism to be the alternative cell death pathway of necroptosis. Caspases, particularly caspase-8, have been implicated as negative regulators of programmed necrosis through cleavage of Rip-kinases. ${ }^{6}$ Recent work underlines this anti-necroptotic role, as embryonic lethality in caspase-8-deficient mice was rescued by also knocking out the necroptosis mediator Rip3 kinase. $^{32}$ Generally, necroptosis is studied using caspase inhibitors (e.g., zVAD-FMK) to allow robust activation of this alternative death pathway, ${ }^{11}$ although necroptosis has been reported to occur without caspase inhibitors. ${ }^{12}$ In macrophages, we find that ZVAD enhanced SM-induced death of macrophages (Figure 2) but caspase inhibition was not necessary for macrophage necroptosis. The endogenous modulator of caspase-8, FLIP, can also regulate necroptosis, with the FLIP-long form inhibiting necroptosis ${ }^{33}$ while FLIPshort increases necroptosis. ${ }^{28}$ Interestingly, we see a minor and transient induction of FLIP-short following SM treatment of macrophages, although it remains unclear whether this is important in SM-induced necroptosis. Thus, it appears that clAPs and caspases cooperate to protect macrophages from necrotic cell death.

$\mathrm{XIAP}$ is a strong endogenous inhibitor of caspases ${ }^{34}$ but its role in necroptotic cell death is yet to be studied. We found that xIAP-deficient macrophages were significantly more sensitive to SM-induced cell death. However, unlike in WT cells, necrostatin was unable to rescue this SM-induced cell death. On the basis of this, we infer that in the absence of xIAP, SM may induce apoptotic rather than necroptotic cell death. Recently, it was shown that xIAP can inhibit the formation of an apoptotic 'ripoptosome' involving both Rip-1 kinase and caspase- $8^{35}$ This may explain enhanced SM-induced non-necroptotic cell death in xIAP-deficient macrophages. Taken with the finding that ZVAD enhanced SM-induced necroptosis, this leads the intriguing possibility that xIAP may selectively inhibit apoptotic activity while allowing anti-necroptotic caspase activity. Thus, our results indicate that $x$ IAP expression in macrophages inhibits SM-induced apoptosis, whereas clAP1 or clAP2 limit alternative death through the necroptosis pathway.

Most studies examining SM-mediated death in tumor cells have found death occurs in concert with TNF- $\alpha$ signaling. ${ }^{36,37}$ Consistent with these previous findings, we observed no significant induction of cell death or change in the Rip1 activation within SM-treated TNFR1/2 ${ }^{-1-}$ macrophages. Interestingly, TNFR1/2 ${ }^{-} /^{-}$macrophages showed elevated basal levels of Rip kinases, suggesting that the receptor may also have a role in the degradation of Rips.

Although clAPs were initially identified as direct inhibitors of caspases, ${ }^{22}$ recent work highlights alternative roles for clAPs as E3-ubiquitin ligases for Rip1. Ubiquitinated Rip1 has limited pro-necrotic kinase activity and is involved in pro-survival NF- $\mathrm{B}$ signaling. ${ }^{14}$ Intruigingly, only a single band for Rip1 was co-immunoprecipitated with clAP in untreated macrophages, corresponding with the unphosphorylated form of Rip1. In addition, we saw that phosphorylation of Rip1 rapidly 
increased after SM treatment. These results underscore the role of clAPs in regulating Rip-1 induction of necroptosis.

Upon SM treatment, Rip3 and to a lesser extent Rip1 showed increased expression. Similarly, increased Rip3 expression in necroptotic cells has recently been reported, ${ }^{38}$ and analysis of different cell lines has shown that sensitivity to TNF- $\alpha / z V A D-F M K$-induced necrosis is determined by Rip3 expression. ${ }^{11}$ Quantitative RT-PCR revealed that upregulation of Rips following SM treatment is likely post-transcriptional. Furthermore, treatment of cells with a caspase inhibitor or 20 s proteasome inhibitor (lactacystin) resulted in increased expression of Rip3 and Rip1 (Supplemental Figure 3). Thus, our data suggest that clAPs may regulate necroptosis through promoting proteolytic degradation of Rips, potentially via multiple pathways.

It is clear that clAPs promote cell death resistance within some tumor cells, but what is the role of clAPs in healthy cells? Recently, one study showed that clAP1-deficient mice have higher $C$. pneumoniae burden, ${ }^{39}$ but the in vivo viability of macrophages was not assessed. Their finding of reduced macrophage numbers in infected lungs of knockout mice is consistent with possible increased cell death. Another study has shown that clAP2-deficient mice are highly resistant to LPS-induced shock due to elevated macrophage cell death. ${ }^{40}$ We reveal that the underlying mechanism of the findings in these studies may be increased macrophage necroptosis. It has also recently been shown that a mutation in the caspase11 gene is present clAP1 $^{-1-}$ mice. ${ }^{41}$ While deficient inflammatory cytokine production due to inactive caspase$11^{42}$ could explain the defects in immune response we have observed, clAP2 ${ }^{-1-}$ mice, which have WT caspase-11, ${ }^{41}$ show similar changes in macrophage cell death and elevated bacterial burden.

It has been suggested that necrotic cell death may be important in initiating immune response. Consistent with this, a study utilizing Rip3-deficient mice showed little necrotic pathology during vaccinia virus infection, but mice also lacked appropriate immune response and succumbed to elevated bacterial load. ${ }^{26}$ Cytomegalovirus has also been demonstrated to avoid immune activation by inhibiting Rip3 as a key survival mechanism. ${ }^{43}$ In contrast to this role, our data show that overactive necroptosis impairs immune control of a bacterial infection. Specifically, lower expression of clAP in vivo resulted in significantly elevated macrophage death and bacterial burden. Limiting macrophage necroptosis via clAP expression appears important in mounting an effective response to LM and is likely an important consideration in other bacterial infections.

In conclusion, we have provided novel mechanistic insights into how clAPs protect macrophages from cell death, through direct interaction with key members of the necrosome. Because activated macrophages can carry elevated levels of ROS and other cytotoxic inflammatory mediators, it is possible that the action of caspases and clAPs may represent and important mechanism to counteract a natural predisposition toward necrotic cell death. In addition, although SM is generally thought to eliminate tumor cells through apoptosis triggered by the degradation of clAPs, it is conceivable that the pathway we have revealed for macrophages may also operate in some tumor cells.

\section{Materials and Methods}

All animals were housed in the animal facility of the Institute for Biological Science and maintained according to CCAC guidelines. Protocols and procedures were approved and monitored by the National Research Council of Canada-Institute for Biological Sciences Animal Care and Ethics Board.

Mice and infections. C57BL/6J mice and TNFR1/2 ${ }^{-1-}$ (Jax \#003243) were obtained at 4-8 weeks of age from Jackson Labs (Bar Harbor, ME, USA). Ageand sex-matched cIAP1 ${ }^{-1-}, 44 \mathrm{CIAP}^{-1-40}$ and WT C57BL/6J were used for in vivo infection and bone marrow macrophage experiments. XIAP mice were also utilized with age-matched control (C57BL/6J) mice. LM strain 10403S was administered in $200 \mu$ l of saline intraperitoneally. For experiments where peritoneal cells or bacterial burdens were examined, peritoneal lavage was performed by killing mice before exposing the peritoneal membrane. The peritoneal cavity was then washed with $10 \mathrm{ml}$ of PBS 4-5 times before removing the liquid and placing immediately on ice. Bacterial colony-forming units (CFU) assessment was performed by diluting peritoneal lavage, or splenic suspension to varying extent in saline and plating on BHI-agar plates. CFU numbers were then counted after incubation for $24 \mathrm{~h}$ at $37^{\circ} \mathrm{C}$.

SM and various inhibitors. SM, SM-164 was generated as described previously. ${ }^{21} \mathrm{SM}-164$ was dissolved at $5 \mathrm{mM}$ in PBS and frozen at $-80^{\circ} \mathrm{C}$. Various specific inhibitors used include z-VAD-FMK (EMD Millipore, Billerica, MA, USA; 627610), caspase-8 inhibitor (EMD Millipore; 218773) and Nec-1 (Sigma-Aldrich Canada Ltd, Oakville, ON, Canada; 9037).

RNA interference. siRNA was synthesized by Dharmacon (Thermo Fisher Scientific Ltd, Nepean, ON, Canada; L-049919-00-0005). A pool of four Rip3targeted siRNA sequences were utilized: 5'-UCAAGAUCGUGAACUCGAA-3', 5'-CAAGUUCGGCCAAGUAUGA-3', 5'-GGUAAAGCAUUAUCUGUCU-3', 5'-ACA CGGCACUCCUUGGUAU- $3^{\prime}$. Negative control siRNA was also obtained from Dharmacon (D-001810-10-05). siRNA knockdown was performed according to manufacturer's protocol. In brief, $0.2 \mu \mathrm{l}$ of transfection reagent (Thermo Scientific, T-2004-02) was combined with siRNA in $20 \mu \mathrm{l}$ of serum-free media and incubated for $20 \mathrm{~min}$ at room temperature. In all, $80 \mu \mathrm{l}$ of media with $8 \%$ FBS was then added to the transfection mixture with a final siRNA concentration of $100 \mathrm{nM}$, and placed on $2 \times 10^{4} \mathrm{~J} 774 \mathrm{~A} 1$ cells in $96-$ well plates. Cells were then incubated for 2 days before examination by western blot, or addition of SM.

Quantitative RT-PCR. RNA for qRT-PCR was isolated from BMDMs at various times after SM treatment. RNA was converted to CDNA using Superscript III Reverse Transcriptase (Invitrogen, Burlington, ON, Canada; 18080-044). cDNA was then analyzed for using Sybr green fast method performed on an Applied Biosystems (Burlington, ON, Canada) 7500-Fast qRTPCR System. The primers used were as follows: Actin (+) 5'-CGCCCTAGGCACCAGGGTGTG $(-)$ TCGGTGAGCAGCA CAGGGTG-3', Rip1 (+) 5'-GCCCAACCGCGCTGAGTACA (-) TGCCTTC TATGGCCTCCACGA-3', Rip3 (+ ) 5'-TGTCAAGTTATGGCCTACTGGTGCG ( - ) AACCATAGCCTTCACCTCCCAGGAT-3'

Isolation of cells from various organs. Cells were isolated from C57BL/6J mice using magnetic cell separation procedure. Peritoneal lavage was performed and spleens were removed. Peritoneal cells were placed in singlecell suspension in PBS with 1\% BSA, then stained using anti-F4/80 PE (BD Biosciences, Franklin Lakes, NJ, USA; 123109). Magnetic isolation was then performed using anti-PE magnetic beads (StemCell Technologies Inc., Vancouver, BC, Canada; 18554). Purification was performed according to manufacturer's protocol. Cell purity was confirmed to be $>90 \%$ by flow cytometry.

Bone marrow macrophages. In order to obtain primary macrophages for in vitro experiments, mouse bone marrow was used as a cell source. In brief, mouse femurs and radius were removed and flushed to remove bone marrow. Cells were then placed in RPMl with $8 \%$ FBS. M-CSF was added at $5 \mathrm{ng} / \mathrm{ml}$ and non-adherent cells were removed on days 2 and 4 . Adherent cells were maintained with regular feeding and cytokine replenishment for 1 week to allow cell differentiation. Flow cytometry was used to confirm the purity of macrophages $\left(\mathrm{F} 4 / 80^{+} / \mathrm{CD} 11 \mathrm{~b}^{+}\right)$.

SDS-PAGE and western blotting. Cell lysates were obtained during various experiments by lysing cells directly in Laemli buffer with $0.5 \%$ 
$\beta$-mercaptoethanol and boiling immediately to minimize protein degradation. SDSPAGE and PVDF membrane transfer was performed by standard protocol. Western blotting was performed with varying concentrations of primary antibody (according to manufacturer's instructions) overnight in 5\% BSA in PBS. Washes were done using PBS with $0.5 \%$ Tween-20 before probing with appropriate secondary antibody for $2 \mathrm{~h}$. Finally, blots were visualized using photosensitive film (Sigma-Aldrich, Carestream Health 785019). Alternatively, bound primary antibodies were reacted with secondary antibodies conjugated with Alexa Fluor680 (Invitrogen) or with IRDyeTM800 (Rockland, Gilbertsville, PA, USA) and the infrared fluorescent signals were detected using the Odyssey Infrared Imaging System (LI-COR Biosciences, Lincoln, NE, USA). In order to ensure true staining for clAPs a number of different antibodies were used. Anti-clAP1/2 antibodies were obtained both from Santa Cruz Biotechnology (Santa Cruz, CA, USA) (sc-12410), and Abcam (ab23423-100). It should be noted that although the Abcam (Cambridge, MA, USA) anti-clAP antibody is listed to detect only cIAP2, we visualized two bands, consistent with both CIAP1 and cIAP2. Rabbit anti-rat IAP1 and IAP3 polyclonal antibodies were also used to detect CIAP1/2 and XIAP, respectively (as described in Mahoney et al..$^{10}$ ). Other antibodies used are as follows: anti-Rip1 (BD 610458), anti-Rip3 (Santa Cruz Biotechnology sc47364) and anti-beta actin (Sigma-Aldrich clone $A C-15)$. Secondary antibodies used were goat anti-mouse IgG HRP (Bio-Rad Life Sciences, Mississauga, ON, Canada; 172-1011), goat anti-rabbit IgG HRP (Sigma-Aldrich A6154) and donkey anti-goat HRP. Detection was performed using Pierce ECL reagent (Thermo Scientific \#32209) or the highly sensitive West Femto ECL for proteins with low expression such as Rip3 (Thermo Scientific \#34095). Phosphatase treatments were performed using 500 units of lambda phosphatase (Santa Cruz Biotechnology sc-200312) for $30 \mathrm{~min}$ at $30^{\circ} \mathrm{C}$.

Immunoprecipitation. Cell lysates from in vitro cell cultures were centrifuged and washed carefully using PBS in order to maintain dead cells. Cells were then lysed using RIPA buffer containing a protease inhibitor cocktail (Roche Applied Science, Laval, QC, Canada; 04693132001) and phosphatase inhibitor cocktail (Sigma-Aldrich P5726). Pre-clearing was performed using isotype IgG control antibody (BD 556026) and protein-G beads (GE Healthcare, Waukesha, WI, USA; 51-3478-CO-EG). Primary antibody was then added and samples were incubated overnight at $4{ }^{\circ} \mathrm{C}$. Immunoprecipitation was completed by adding protein- $\mathrm{G}$ beads, incubating for $2 \mathrm{~h}$ on ice, and washing several times with PBS. For clAP experiments, anti-cIAP2 (Abcam) was used for immunoprecipitation. Finally, immunoprecipitates were denatured by adding Laemli buffer with $0.5 \% \beta$-mercaptoethanol and boiling before performing a western blot analysis as described above.

Viability (MTT) assay. Cell viability was assessed using the MTT assay. MTT reagent was added to cells at a final concentration of $0.5 \mathrm{mg} / \mathrm{ml}$ and incubated at $37^{\circ} \mathrm{C}$ for $4 \mathrm{~h}$. Cells were then lysed and the MTT crystals solubilized using $2 \mathrm{~N} \mathrm{HCl}$ in isopropyl alcohol. Results were quantified by measuring absorption at $570 \mathrm{~nm}$ with a reference wavelength of $650 \mathrm{~nm}$.

Cell death assay (LDH release). Cell death was assessed using a commercial LDH release assay (Sigma-Aldrich \#TOX7). Supernatants were collected from SM-treated cell cultures and subjected to analysis for total LDH according to manufacturer's instructions.

FACS and fluorescence microscopy. Viability analysis was performed using live-cell flow cytometric staining. Cells were first placed in single-cell suspension in $1 \%$ BSA in PBS. To assess viability, in vitro cell suspensions were stained by adding $10 \mu \mathrm{l}$ of Pl/RNAse solution (BD 51-6551AZ) and incubating for $15 \mathrm{~min}$ at $37^{\circ} \mathrm{C}$ before reading. Cells obtained from mice were first labeled with various antibodies, including anti-F4/80 APC-Cy7 (BioLegend, San Diego, CA, USA; 122614), anti-CD11b PE-Cy7 (BD 552850), and anti-CD3 APC (BD 557030). After 20 min of incubation with antibodies, $\mathrm{PI}$ was added to cells as described above. Cells were then examined using a BD FACSCanto Flow cytometer. Fluorescence microscopy was performed using similar staining techniques with cells placed in HBSS instead of PBS. Cells were examined using an Olympus IX81 fluorescent microscope (Olympus, Richmond Hill, ON, Canada). Live fluorescence microscopy was performed under controlled incubation conditions with images captured every $30 \mathrm{~s}$ over an extended time period.

For confocal microscopy experiments, cells were fixed using $4 \%$ paraformaldehyde, permeabilized using $0.4 \%$ Triton X-100, and stained with TNFR1 (Santa Cruz Biotechnology SC-1070), Rip1 and Rip3 antibodies (as described above).
Fluorescent goat-anti rabbit Alexa-fluor 488 (Invitrogen A11070) and goat antimouse Alexa-fluor 594 (Invitrogen A11020) were then used. Appropriate controls without primary antibody staining were used to confirm specificity. Images were captured using an extended focus image constructed from 10 exposures on the Olympus Fluoview 1000 instrument.

Statistics. Statistical analysis was performed using GraphPad Prism 5 (La Jolla, CA, USA). Student's $t$ test was used to confirm significance of results. All error bars shown indicate standard error of the mean (S.E.M.).

\section{Conflict of Interest}

The authors declare no conflict of interest.

Acknowledgements. This work was supported by grants from the Canadian Institutes of Health Research (SS) and the Ontario Institute for Cancer Research (LK).

1. Janeway C-AJ. How the immune system works to protect the host from infection: a personal view. Proc Natl Acad SciU SA 2001; 98: 7461-7468.

2. Jay Forman H, Torres M. Redox signaling in macrophages. Mol Aspects Med 2001; 22: 189-216.

3. Perlman H, Pagliari LJ, Georganas C, Mano T, Walsh K, Pope RM. FLICE-inhibitory protein expression during macrophage differentiation confers resistance to Fas-mediated apoptosis. J Exp Med 1999; 190: 1679-1688.

4. Mangan DF, Wahl SM. Differential regulation of human monocyte programmed cell death (apoptosis) by chemotactic factors and pro-inflammatory cytokines. J Immunol 1991; 147: 3408-3412.

5. Sordet $O$, Rebe C, Plenchette S, Zermati Y, Hermine O, Vainchenker W et al. Specific involvement of caspases in the differentiation of monocytes into macrophages. Blood 2002; 100: 4446-4453.

6. Christofferson DE, Yuan J. Necroptosis as an alternative form of programmed cell death. Curr Opin Cell Biol 2010; 22: 263-268.

7. Festjens N, Vanden Berghe T, Vandenabeele P. Necrosis, a well-orchestrated form of cell demise: signalling cascades, important mediators and concomitant immune response. Biochim Biophys Acta 2006; 1757: 1371-1387.

8. Degterev A, Huang Z, Boyce M, Li Y, Jagtap P, Mizushima N et al. Chemical inhibitor of nonapoptotic cell death with therapeutic potential for ischemic brain injury. Nat Chem Bio 2005; 1: 112-119.

9. Declercq W, Vanden Berghe T, Vandenabeele P. RIP kinases at the crossroads of cell death and survival. Cell 2009; 138: 229-232.

10. Mahoney DJ, Cheung HH, Mrad RL, Plenchette S, Simard C, Enwere E et al. Both clAPI and CIAP2 regulate TNFalpha-mediated NF-kappaB activation. Proc Natl Acad Sci USA 2008; 105: 11778-11783.

11. He S, Wang L, Miao L, Wang T, Du F, Zhao L et al. Receptor interacting protein kinase-3 determines cellular necrotic response to TNF-[alpha]. Cell 2009; 137: 1100-1111.

12. Vanlangenakker $\mathrm{N}$, Vanden Berghe $\mathrm{T}$, Bogaert $\mathrm{P}$, Laukens $\mathrm{B}$, Zobel $\mathrm{K}$, Deshayes $\mathrm{K}$ et al. CIAPI and TAK1 protect cells from TNF-induced necrosis by preventing RIP1/RIP3dependent reactive oxygen species production. Cell Death Differ 2011; 18: 656-665.

13. Vandenabeele P, Declercq W, Van Herreweghe F, Vanden Berghe $T$. The role of the kinases RIP1 and RIP3 in TNF-induced necrosis. Sci Signal 2010; 3: re4.

14. Bertrand MJM, Milutinovic S, Dickson KM, Ho WC, Boudreault A, Durkin J et al. clAP1 and CIAP2 facilitate cancer cell survival by functioning as E3 ligases that promote RIP1 ubiquitination. Mol Cell 2008; 30: 689-700.

15. Temkin V, Karin M. From death receptor to reactive oxygen species and c-Jun N-terminal protein kinase: the receptor-interacting protein 1 odyssey. Immunol Rev 2007; 220: 8-21.

16. Divangahi M, Chen M, Gan H, Desjardins D, Hickman TT, Lee DM et al. Mycobacterium tuberculosis evades macrophage defenses by inhibiting plasma membrane repair. Nat Immunol 2009; 10: 899-906.

17. Stockinger S, Decker T. Novel functions of type I interferons revealed by infection studies with Listeria monocytogenes. Immunobiology 2008; 213: 889-897.

18. Igney FH, Krammer PH. Death and anti-death: tumour resistance to apoptosis. Nat Rev Cancer 2002; 2: 277-288.

19. Yashi M, Muraishi O, Kobayashi Y, Tokue A, Nanjo H. Inhibitors of apoptosis proteins in prostate cancer cell lines. Prostate 2002; 51: 133-140.

20. Busca A, Saxena M, Kryworuchko M, Kumar A. Anti-Apoptotic genes in the survival of monocytic cells during infection. Curr Genomics 2009; 10: 306-317.

21. Lu J, Bai L, Sun H, Nikolovska-Coleska Z, McEachern D, Qiu S et al. SM-164: a novel, bivalent $\mathrm{Smac}$ mimetic that induces apoptosis and tumor regression by concurrent removal of the blockade of cIAP-1/2 and XIAP. Cancer Res 2008; 68: 9384-9393.

22. Roy N, Deveraux QL, Takahashi R, Salvesen GS, Reed JC. The c-IAP-1 and c-IAP-2 proteins are direct inhibitors of specific caspases. EMBO J 1997; 16: 6914-6925. 
23. Eckelman BP, Salvesen GS. The human anti-apoptotic proteins CIAP1 and cIAP2 Bind but do not inhibit caspases. J Biol Chem 2006; 281: 3254-3260.

24. Degterev A, Hitomi J, Germscheid M, Ch'en IL, Korkina O, Teng X et al. Identification of RIP1 kinase as a specific cellular target of necrostatins. Nat Chem Biol 2008; 4: 313-321.

25. Suzuki Y, Nakabayashi Y, Nakata K, Reed JC, Takahashi R. X-linked inhibitor of apoptosis protein (XIAP) Inhibits caspase-3 and -7 in distinct modes. J Biol Chem 2001; 276: 27058-27063.

26. Cho YS, Challa S, Moquin D, Genga R, Ray TD. Phosphorylation-driven assembly of the RIP1-RIP3 complex regulates programmed necrosis and virus-induced inflammation. $\mathrm{Cell}$ 2009; 137: 1112-1123

27. Lee TH, Shank J, Cusson N, Kelliher MA. The kinase activity of Rip1 is not required for tumor necrosis factor-alpha-induced IkappaB kinase or p38 MAP kinase activation or for the ubiquitination of Rip1 by Traf2. J Biol Chem 2004; 279: 33185-33191.

28. Feoktistova M, Geserick P, Kellert B, Dimitrova DP, Langlais C, Hupe M et al. clAPs block ripoptosome formation, a RIP1/caspase-8 containing intracellular cell death complex differentially regulated by cFLIP isoforms. Mol Cell 2011; 43: 449-463.

29. Mocci S, Dalrymple SA, Nishinakamura R, Murray R. The cytokine stew and innate resistance to L. monocytogenes. Immunol Rev 1997; 158: 107-114.

30. Cui X, Imaizumi T, Yoshida H, Tanji K, Matsumiya T, Satoh K. Lipopolysaccharide induces the expression of cellular inhibitor of apoptosis protein-2 in human macrophages. Biochim Biophys Acta 2000; 1524: 178-182.

31. Muller-Sienerth N, Dietz L, Holtz P, Kapp M, Grigoleit GU, Schmuck C et al. SMAC mimetic BV6 induces cell death in monocytes and maturation of monocyte-derived dendritic cells. PLOS ONE 2011; 6: e21556.

32. Kaiser WJ, Upton JW, Long AB, Livingston-Rosanoff D, Daley-Bauer LP, Hakem R et al. RIP3 mediates the embryonic lethality of caspase-8-deficient mice. Nature 2011; 471: 368-372.

33. Oberst A, Dillon CP, Weinlich R, McCormick LL, Fitzgerald P, Pop C et al. Catalytic activity of the caspase-8-FLIP(L) complex inhibits RIPK3-dependent necrosis. Nature 2011; 471 363-367.
34. Eckelman BP, Salvesen GS, Scott FL. Human inhibitor of apoptosis proteins: why XIAP is the black sheep of the family. EMBO Rep 2006; 7: 988-994.

35. Tenev T, Bianchi K, Darding M, Broemer M, Langlais C, Wallberg F et al. The ripoptosome, a signaling platform that assembles in response to genotoxic stress and loss of IAPs. Mol Cell 2011; 43: 432-448.

36. Probst BL, Liu L, Ramesh V, Li L, Sun H, Minna JD et al. Smac mimetics increase cance cell response to chemotherapeutics in a TNF-alpha-dependent manner. Cell Death Differ 2010; 17: 1645-1654.

37. Wu H, Tschopp J, Lin SC. Smac mimetics and TNFalpha: a dangerous liaison? Cell 2007; 131: $655-658$.

38. Davis CW, Hawkins BJ, Ramasamy S, Irrinki KM, Cameron BA, Islam K et al. Nitration of the mitochondrial complex I subunit NDUFB8 elicits RIP1- and RIP3-mediated necrosis. Free Radic Biol Med 2010; 48: 306-317.

39. Prakash H, Becker D, Böhme L, Albert L, Witzenrath M, Rosseau S et al. clAP-1 controls innate immunity to $\mathrm{C}$. pneumoniae pulmonary infection. PLOS ONE 2009; 4: e6519.

40. Conte D, Holcik M, Lefebvre CA, LaCasse E, Picketts DJ, Wright KE et al. Inhibitor of apoptosis protein cIAP2 Is essential for lipopolysaccharide-induced macrophage survival. $\mathrm{Mol}$ Cell Biol 2006; 26: 699-708.

41. Kenneth NS, Younger JM, Hughes ED, Marcotte D, Barker PA, Saunders TL et al. An inactivating caspase-11 passenger mutation originating from the 129 murine strain in mice targeted for c-lap1. Biochem J 2012; 443: 355-359.

42. Kayagaki N, Warming S, Lamkanfi M, Vande WL, Louie S, Dong J et al. Non-canonical inflammasome activation targets caspase-11. Nature 2011; 479: 117-121.

43. Upton JW, Kaiser WJ, Mocarski ES. Virus inhibition of RIP3-dependent necrosis. Cell Host Microbe 2010; 7: 302-313.

44. Conze DB, Albert L, Ferrick DA, Goeddel DV, Yeh WC, Mak T et al. Posttranscriptional downregulation of C-IAP2 by the ubiquitin protein ligase C-IAP1 in vivo. Mol Cell Biol 2005; 25: $3348-3356$.

Supplementary Information accompanies the paper on Cell Death and Differentiation website (http://www.nature.com/cdd) 